\title{
Scrap the cap on overseas doctors
}

\author{
Tom Moberly UK editor
}

The BMJ

Since its inception 70 years ago the NHS has relied on doctors who trained in other countries. Today, one in three doctors working in the UK trained abroad, and one in four trained outside Europe. Crucially, these doctors have often worked in areas that home grown doctors haven't wanted to, as Julian Simpson reflects in an essay this week (doi:10.1136/bmj.k2336).

But the number of overseas trained doctors working in the UK is falling-by $7 \%$ in the past five years—as more are choosing to leave the UK. Successive governments have pursued policies to reduce net migration, and current immigration restrictions are making things worse.

Between December 2017 and March 2018 the Home Office refused over 1500 visa applications from doctors (doi:10.1136/ bmj.k2362). The numbers being refused, despite these doctors having offers of NHS jobs, rose month on month over that period, from 266 in December 2017 to 487 in March 2018.

This makes no sense. The NHS needs doctors from overseas. Pressures on the health service are growing, and rota gaps and unfilled vacancies are damaging the care of patients and staff morale.

As the chief executive of NHS Employers points out (doi:10. 1136/bmj.k2372), restricting the entry of foreign doctors piles up pressure on staff, pushes up spending on locums, and hinders the delivery of safe patient care.

The current situation can't continue. It is a waste of precious resources to recruit foreign doctors and pay visa sponsorship fees, only to have visas refused. The NHS has many posts that it is struggling to fill. It must be able to look to suitably qualified doctors from other countries. The rules that stop that happening need to change.

These concerns have prompted us to launch our Scrap the Cap campaign (bmj.com/scrap-the-cap). We are calling for an urgent change to immigration policies so that doctors from abroad can take up the NHS posts they have been offered. The BMA, several royal medical colleges, and NHS Employers have pledged their support, and we hope that other medical organisations will follow suit.

As part of the campaign we've set up a petition calling for the UK government and parliament to remove visa restrictions that prevent international doctors from working in the UK (http:// bit.ly/2JffJd2).

Please sign it. 